\title{
Thermal Decomposition of Mercerized Linter Cellulose and its Acetates Obtained from a Homogeneous Reaction
}

\author{
Daniella L. Morgado, Elisabete Frollini \\ Instituto de Química de São Carlos, USP
}

\begin{abstract}
Cellulose acetates with different degrees of substitution (DS, from 0.6 to 1.9) were prepared from previously mercerized linter cellulose, in a homogeneous medium, using $N, N$-dimethylacetamide/lithium chloride as a solvent system. The influence of different degrees of substitution on the properties of cellulose acetates was investigated using thermogravimetric analyses (TGA). Quantitative methods were applied to the thermogravimetric curves in order to determine the apparent activation energy (Ea) related to the thermal decomposition of untreated and mercerized celluloses and cellulose acetates. Ea values were calculated using Broido's method and considering dynamic conditions. Ea values of 158 and $187 \mathrm{~kJ} \mathrm{~mol}^{-1}$ were obtained for untreated and mercerized cellulose, respectively. A previous study showed that $\mathrm{C} 6 \mathrm{OH}$ is the most reactive site for acetylation, probably due to the steric hindrance of $\mathrm{C} 2$ and $\mathrm{C} 3$. The $\mathrm{C} 6 \mathrm{OH}$ takes part in the first step of cellulose decomposition, leading to the formation of levoglucosan and, when it is changed to $\mathrm{C} 6 \mathrm{OCOCH}_{3}$, the results indicate that the mechanism of thermal decomposition changes to one with a lower Ea. A linear correlation between Ea and the DS of the acetates prepared in the present work was identified.
\end{abstract}

Keywords: Linter cellulose, cellulose acetates, thermal decomposition.

\section{Decomposição Térmica de Celulose de Linter Mercerizado e seus Acetatos Obtidos a partir de Reação Homogênea}

Resumo: Acetatos de celulose com graus de substituição, GS, variando entre 0,6 e 1,9, foram preparados previamente a partir de celulose de linter mercerizado, em meio homogêneo, usando $N, N$-dimetilacetamida/cloreto de lítio como sistema de solvente. A influência de diferentes graus de substituição nas propriedades dos acetatos de celulose foi investigada usando a análise termogravimétrica (TGA). Métodos quantitativos foram aplicados nas curvas termogravimétricas obtidas a fim de determinar a energia de ativação aparente (Ea) relacionado à decomposição térmica de celulose não-tratada e mercerizada e acetatos de celulose. Valores de Ea foram calculados usando o método de Broido e considerando condições dinâmicas. Valores de Ea de 158 e $187 \mathrm{~kJ} \mathrm{~mol}^{-1}$ foram obtidos para a celulose não-tratada e mercerizada, respectivamente. Em trabalho anterior verificou-se que o $\mathrm{C} 6 \mathrm{OH}$ é o sítio mais reativo na acetilação, provavelmente devido ao impedimento estérico de $\mathrm{C} 2$ e C3. O C6OH participa da primeira etapa de decomposição da celulose, levando à formação de levoglucosana e, quando se tem a substituição para $\mathrm{C} \mathrm{OCOCH}_{3}$, o resultado indica que o mecanismo de decomposição térmica muda para um com Ea menor. Uma correlação linear entre Ea e o GS dos acetatos preparados no presente trabalho foi identificada.

Palavras-chave: Celulose de linter, acetatos de celulose, decomposição térmica.

\section{Introduction}

Cellulose, the most abundant naturally occurring polysaccharide, is renewable, biodegradable, and can be derivatized to yield various useful products ${ }^{[1-3]}$. Cellulose is a linear homopolymer consisting of $\beta$-(1-4)-linked anhydroglucopyranose units (AGU). The wood is the main source of cellulose and it is considered a slowly regenerated raw material, because of the time required for a tree may be cut to produce cellulose $\mathrm{e}^{[4]}$. In contrast, cellulose from other raw materials, such as cotton, has become attractive as a source for cellulose derivatives, because it is available in large quantities, and is routinely cultivated around the world.

Cellulose is not soluble in conventional solvents, mainly due to the complex morphology of the crystalline regions and to interand intramolecular hydrogen bonds. The substitution of hydroxyl groups presents of the cellulose chains by less polar groups, aiming at the solubilization after derivatization, is very usual ${ }^{[5]}$. The aprotic polar solvent ( $N, N$-dimethylacetamide) in combination with an inorganic salt, preferably lithium chloride $(\mathrm{LiCl})^{[6]}$, is able to dissolve cellulose. The impetus behind investigating this solvent system for cellulose derivatization under homogeneous reaction has been extensively described in the literature ${ }^{[7-13]}$. The homogeneous reaction involves several steps, including cellulose activation, dissolution, and subsequent reaction with a derivatizing agent $^{[10]}$.

The derivatization of cellulose in a homogeneous reaction, as considered in the present work, is advantageous compared to a heterogeneous reaction, due to the ability to control the degree of substitution (DS) and regularity of substitution, both along the polymer backbone and among the three $\mathrm{OH}$ groups of the anhydroglucose unit (AGU). This reaction can be produced by employing materials with well-defined characteristics and through a method with good reproducibility, which allows the production a material with better properties ${ }^{[10,12,14-17]}$. The cellulose from cotton linters used in the present study has a high degree of crystalline order, in consequence of this the polymer chains are closely packed and can only be dissolved in $\mathrm{DMAc} / \mathrm{LiCl}$ after a pre-treatment with alkaline solution (mercerization) ${ }^{[10]}$.

The pre-treatment with alkali solution irreversibly convert the cellulose I into the second most extensively studied allomorph, cellulose II. The studies involving ${ }^{13} \mathrm{C}$ CPMAS solid state NMR showed the highly crystalline structure of cellulose I and present the coexistence of two crystal phases: cellulose I $\alpha$ and cellulose I $\beta$. The crystalline phases I $\alpha$ e I $\beta$ can occur in different amounts depending on the origin of the cellulose ${ }^{[18]}$. 
The cellulose I chains has a higher mobility, when swelled by $\mathrm{NaOH}$, allowing them to rotate about their axes, producing the antiparallel structure, characteristic of cellulose $\mathrm{II}^{[19]}$. This change is due to the fact that the hydroxymethyl group $\left(-\mathrm{CH}_{2} \mathrm{OH}\right)$ can assumes different conformations, generating two different packing structures of cellulose chains in a microcrystal. The parallel chain structure, characteristic of cellulose I, occurs when the -adjacent chains have the $\mathrm{CH}_{2} \mathrm{OH}$ groups in the same conformation. The antiparallel structure, characteristic of cellulose II, occurs when the adjacent chains have the $-\mathrm{CH}_{2} \mathrm{OH}$ groups in different positions ${ }^{[11,19]}$.

The pre-treatment of cellulose with aqueous solutions of $\mathrm{NaOH}$ may form crystallites composed of parallel cellulose chains, incorporating the hydrate sodium and hydroxide ions and to form alkyl cellulose ${ }^{[20]}$. The comprehension of structure of mercerized cellulose has been made using the different techniques, as synchrotron $\mathrm{X}$ ray analysis ${ }^{[21]}$ and $\mathrm{X}$ ray diffraction coupled with ${ }^{13} \mathrm{C}$ CP-MAS NMR ${ }^{[22]}$. These studies support the view that the cellulose I present the parallel mode and the cellulose II the antiparallel structure $^{[11]}$.

Cellulose acetates are some of the most important cellulose esters due their multiple applications, such as in textiles (clothing and fabrics), high absorbency products (diapers, cigarette filters, and other filters), thermoplastics products (films and plastic instruments), food products (food packaging), cosmetics and pharmaceuticals (extended capsule/tablet release agents and encapsulating agents), and medical instruments (hypoallergenic surgical products) ${ }^{[23,24]}$.

The acetylation reaction of cellulose disrupts the intra- and intermolecular interactions within the cellulose chain. When the cellulose is derivatized in a homogenous reaction, the acetate groups in glucopyranose rings can be regularly introduced along the cellulose chains.

Thermogravimetric analysis (TGA) is widely used to investigate the thermal decomposition of polymers and determine some kinetic parameters, e.g., the rate of decomposition, k; the reaction order, $\mathrm{n}$; and the $\mathrm{Ea}^{[25-27]}$. The values of these parameters are of major importance in the identification of the mechanisms involved in polymer decomposition ${ }^{[27,28]}$ and as estimates to the thermal stability of polymers.

The comprehension of cellulose decomposition is important to biomass thermochemical conversion ${ }^{[29]}$; however, the decomposition of cellulose and its derivatives is an extremely complex process, and generally consists of a series of reactions.

Due to the complexity of thermal decomposition of cellulose, studies have attempted to identify the kinetic parameters therein. The identification of the thermal decomposition temperature by TGA defines the upper limits of processing ${ }^{[30]}$ for materials. The usefulness of cellulose acetate can be strongly influenced by its degradation and stabilization ${ }^{[31]}$.

The present study investigates the preparation of cellulose acetates from cotton linters in a homogeneous medium $(\mathrm{N}, \mathrm{N}$ dimethylacetamide/lithium chloride), evaluates the thermal behavior of these cellulose acetates via TGA, and estimates their thermal decomposition apparent activation energy using Broido's equation under nitrogen and dynamic conditions.

\section{Experimental}

\section{Materials and reagents}

The source cellulose material used in this investigation was cotton linters (kindly provided by Industria Fibra S/A, Americana, São Paulo, Brazil) with low degree of polymerization (DP). $\mathrm{N}, \mathrm{N}$ dimethylacetamide (DMAc, Synth) was purified by distillation from $\mathrm{CaH}_{2}$ under nitrogen followed by storage over $4 \AA$ molecular sieves. Acetic anhydride ( $\mathrm{Ac}_{2} \mathrm{O}$, Synth) was also distilled from the appropriate dying agents $\mathrm{P}_{2} \mathrm{O}_{5}$ prior to use. Before the reaction, lithium chloride ( $\mathrm{LiCl}$, Synth) was placed in vacuum oven and dried for 3 hours at $200{ }^{\circ} \mathrm{C}$, and stored in a desiccator.

\section{Cellulose mercerization}

The cellulose mercerization used in this study was established in a previous work ${ }^{[11]}$. Mercerization of linters cellulose was achieved in a solution of $20 \% \mathrm{NaOH}(1: 50 \mathrm{w} / \mathrm{w})$ for 1 hour at $0{ }^{\circ} \mathrm{C}^{[32]}$. After this period, the alkali-swollen was washed with distilled water until it is no more trace of $\mathrm{NaOH}$. The product was kept at room temperature for 24 hours and then dried under vacuum at $60^{\circ} \mathrm{C}$ until constant weight was obtained.

\section{Characterization of cellulose}

\section{Degree of polymerization (DP)}

In order to measure the degree of polymerization (DP), the cellulose samples were solubilized in cooper ethylene diamine solution (CUEN, 1:1 v/v), using an Ostwald viscometer. The average molar mass is given by $\overline{\mathrm{Mv}}=\overline{\mathrm{DP}} \times 162$, according to the TAPPI standard T230 om $-89^{[33]}$.

\section{Crystallinity index}

$\mathrm{X}$ ray diffraction analysis was used to evaluate the crystallinity index of untreated and mercerized celluloses. The diffractogram patterns were obtained in a VEB CARL ZEISS-JENA URD-6 Universal Diffractometer operating with $\mathrm{CuK \alpha}(\lambda=1.5406 \AA)$ generated at $40 \mathrm{kV}$ and $20 \mathrm{~mA}$. The crystallinity index of samples was determined using the method based on Buschle-Diller and Zeronian equation, as described elsewhere ${ }^{[32]}$ :

$$
I_{c}=1-\left(\frac{I_{\min }}{I_{\max }}\right)
$$

where $I_{\min }$ is the minimum intensity of the $10^{\overline{1}}$ lattice at $17^{\circ}$ (amorphous region of native cellulose) or 101 lattice at $15^{\circ}$ (non-crystalline region of mercerized cellulose), and $\mathrm{I}_{\max }$ is the maximum intensity of the 002 lattice at $22^{\circ}$ (attributed to the crystalline region of the sample).

\section{Morphological surface analysis}

Scanning Electron Microscopy (SEM) was carried out with a LEO 440 ZEISS/LEICA model, operating at accelerating voltage of $20 \mathrm{kV}$. The samples were covered with a thin layer of gold prior to analysis.

\section{Thermogravimetric Analyses}

TGAs were carried out in a Shimadzu TGA-50 instrument from samples consisting of untreated and mercerized linters cellulose. Approximately $5.0 \mathrm{mg}$ of sample was weighed on an platinum pan and heated from room temperature to $600{ }^{\circ} \mathrm{C}$ at $20^{\circ} \mathrm{C} / \mathrm{min}$ under a nitrogen flow rate of $20 \mathrm{~mL} / \mathrm{min}$.

\section{Dissolution of the mercerized linters cellulose}

The dissolution procedure used in this study was established in a previous work ${ }^{[10]}$. Standard round-bottomed flask of $250 \mathrm{~mL}$ of capacity was equipped with a stopcock, cylindrical funnel (without equilibration side arm), mechanical stirrer, and condenser closed with a stopper. Linters cellulose $(2.0 \mathrm{~g})$ and $\mathrm{LiCl}(5.0 \mathrm{~g})$ were added into the flask. The flask was immersed in an oil bath, the pressure was reduced $(2 \mathrm{~mm} \mathrm{Hg})$ and the oil bath temperature was heated from room temperature to $110^{\circ} \mathrm{C}$ at $3{ }^{\circ} \mathrm{C} / \mathrm{min}$. The oil bath temperature was externally controlled (FE50RP controller, Flyever, 
São Carlos, São Paulo, Brazil). The mixture was stirred under these conditions for 30 minutes. The vacuum pump was turned off and then slowly DMAc (100.0 mL) was added with vigorous stirring. After the addition of the DMAc under reduced pressure, the system was connected to dry nitrogen and the condenser was provided with a drying tube. The temperature was raised to $150{ }^{\circ} \mathrm{C}$ at $4{ }^{\circ} \mathrm{C} / \mathrm{min}$ and the reaction mixture was stirred in dried nitrogen atmosphere for 90 minutes with mechanical stirrer and condenser with a drying tube. The system was then cooled to $36{ }^{\circ} \mathrm{C}$ at $1{ }^{\circ} \mathrm{C} / \mathrm{min}$.

\section{Acetylation of the cellulose}

The cellulose solution obtained after cooled was heated from room temperature to $110^{\circ} \mathrm{C}$ at $3{ }^{\circ} \mathrm{C} / \mathrm{min}$. The system was maintained under reflux and a flow of dry nitrogen atmosphere. Acetic anhydride $\left(\mathrm{Ac}_{2} \mathrm{O}\right)$ was added drop-wise, according to molar ratios to the anhy-droglucose units (AGU). The system was kept in this temperature $\left(110^{\circ} \mathrm{C}\right)$ for 4 hours, under stirring, reflux and nitrogen flow. After that, the system was cooled to room temperature and further the final product was purified by precipitation in methanol. The resulting precipitate was purified again by Soxhlet extraction in methanol solvent for 7 days. The cellulose acetates were dried at $50{ }^{\circ} \mathrm{C}$ under vacuum oven until constant weight.

\section{Degree of substitution of cellulose acetates}

Proton NMR spectra of cellulose acetates were recorded on a Brucker AC-200 spectrometer operating at $200 \mathrm{MHz}$ at $80{ }^{\circ} \mathrm{C}$ using 392 scans. For this purpose, the cellulose acetates were dissolved in DMSO- $\mathrm{d}_{6}$ at concentration of $10.0 \mathrm{mg} \mathrm{mL}^{-1}$. By the addition of deuterated trifluoro-acetic into the sample solution it is possible shift the signal of residual water and hydroxyl protons to a lower field outside the spectral region of interest without affecting the chemical shifts of the glucose ring protons ${ }^{[11,12,17,24,34]}$.

\section{Thermogravimetric analyses}

The analyses were carried out as described for linters cellulose.

\section{Thermal decomposition of linters cellulose and acetates}

The kinetic of thermal decomposition is typically studied using dynamic and isothermal experiments. In dynamic methods, the samples are heated with a linear heating rate from room temperature until to reach the complete decomposition of material, while isothermal methods are realized in different intervals of time during with careful selection of different temperatures close to the decomposition temperature ${ }^{[35]}$. In the case of untreated linters cellulose, the decomposition of cellulose can be initiated at temperatures lower than $370{ }^{\circ} \mathrm{C}$, while the maximum temperature is around $400{ }^{\circ} \mathrm{C}$.

In order to identify relevant kinetic parameters, particularly the activation energy, various methods can be applied. In kinetic analysis, the thermal decomposition of polymer can be described as occurring by a set of series of reaction and the degree of conversion is given as a function of time $t$ for each isothermal experimental. It is defined by:

$$
-\frac{d(1-\alpha)}{d t}=k(1-\alpha)^{n}
$$

where $\mathrm{n}$ is the reaction order, which is adopted in the present study as first-order kinetics ${ }^{[36]}$ in dynamic conditions, and $\mathrm{k}$ is the rate constant, which is assumed to obey the Arrhenius laws (Equation 3) for the beginning of the reaction:

$$
k=A e^{-E a / R T}
$$

$\alpha$ is the degree of conversion:

$$
\alpha=\frac{W_{e}}{W_{o}}
$$

where $\mathrm{W}_{\mathrm{e}}$ is the mass loss as volatile fragments eliminated from the polymer and $\mathrm{W}_{0}$ is the initial mass.

In the case of an isothermal experiment, MacCallum ${ }^{[37]}$ proposed the following expression for Equation 2:

$$
-\frac{d(1-\alpha)}{d t}=k f(1-\alpha)^{n}
$$

where $\mathrm{f}$ is a function that represents the reaction mechanism ${ }^{[36]}$.

The integration of Equation 5 and followed by substitution in Equation 2 results in:

$$
f(1-\alpha)=A e^{\frac{-E}{R T}} t
$$

which rearranges to:

$$
\frac{E_{a}}{R T}+\ln [f(1-\alpha)]-\ln A=\ln t
$$

If several isothermal experiments are considered, a plot of degree of conversion $v s$. the reciprocal of the temperature of the experiment will result in a straight line the slope of which will be the $\mathrm{Ea} / \mathrm{R}^{[35]}$

In a dynamic experiment, as in the present work, from the initial temperature $\left(\mathrm{T}_{\mathrm{o}}\right)$, the temperature $(\mathrm{T})$ changes linearly as a function of heating rate $(\mathrm{u})$, during the time $t$, then:

$$
\mathrm{T}=\mathrm{T}_{\mathrm{o}}+\mathrm{ut}
$$

A combination of Equations 2, 3, and 8 gives:

$$
\frac{d(1-\alpha)}{(1-\alpha)^{n}}=-\frac{A}{u} e^{\frac{-E}{R T}} d T
$$

which, according to the Broido method ${ }^{[38]}$ can be written as:

$$
\ln \left[\ln \left(\frac{1}{1-\alpha}\right)\right]=\frac{-E_{a}}{R T}+\ln \left[\left(\frac{R}{E_{a}}\right)\left(\frac{Z}{u}\right) T_{m}^{2}\right]
$$

where $\mathrm{T}_{\mathrm{m}}$ is the temperature of the maximum reaction decomposition, $\mathrm{Z}$ is a constant, $\mathrm{U}$ is the heating rate, and $\mathrm{R}$ is the universal gas constant $\left(\mathrm{R}=8.314 \mathrm{~J} \mathrm{~mol}^{-1} \mathrm{~K}^{-1}\right)$. Plotting $\ln [\ln [1 /(1-\alpha)]]$ vs. $1 / \mathrm{T}$ should result in a straight line, the slope of which $-\mathrm{Ea} / \mathrm{R}$ can provide the value of Ea.

\section{Results and discussion}

\section{Cellulose characterization}

The scanning electron micrographs presented in Figure 1 show surfaces of mercerized and untreated cellulose linters.

The surface of mercerized linters is smoother than that of untreated linters, which indicates that there are no fragments stuck to the fibers, suggesting that some fragments have been eliminated during the mercerization procedure. In addition, the fibers bundles seem more separated in mercerized cellulose (Figure 1). Table 1 shows the degree of polymerization (DPv) and crystallinity index (Ic) of untreated and mercerized linters cellulose:

The alkali treatment resulted in a decrease in the degree of the polymerization (DPv) of the cellulose due to the hydrolysis of glycosidic bonds ${ }^{[11]}$. Mercerization also results in higher liquid 


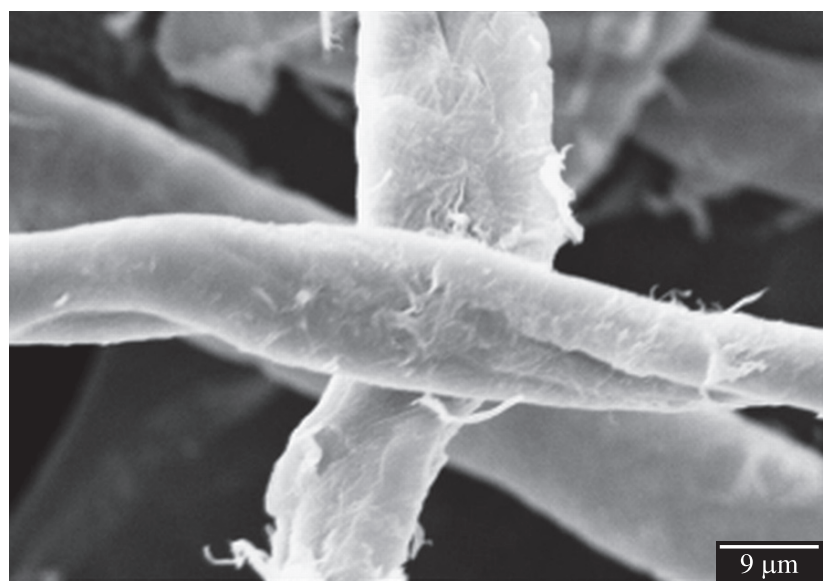

(a)

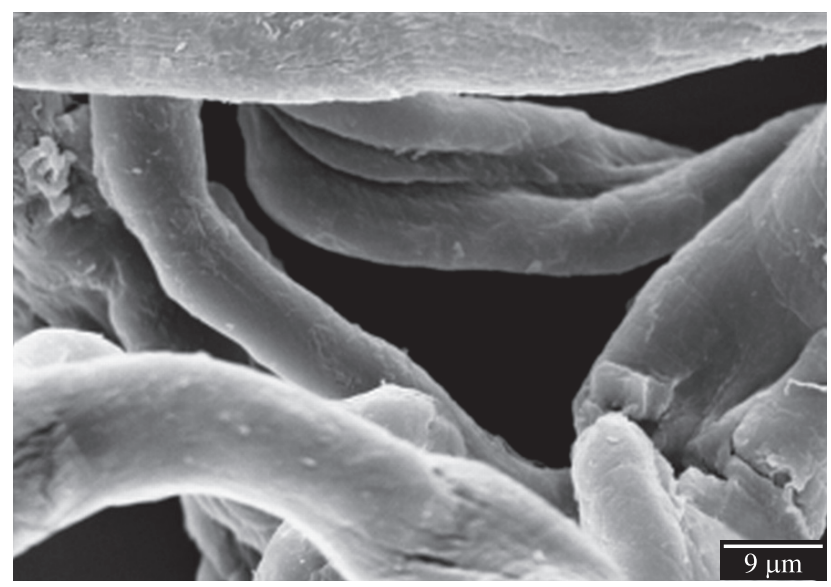

(c)

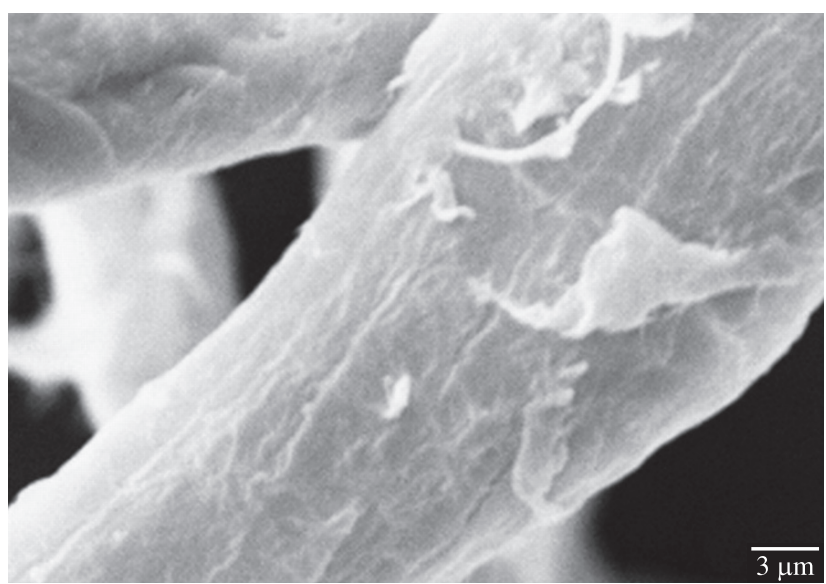

(b)

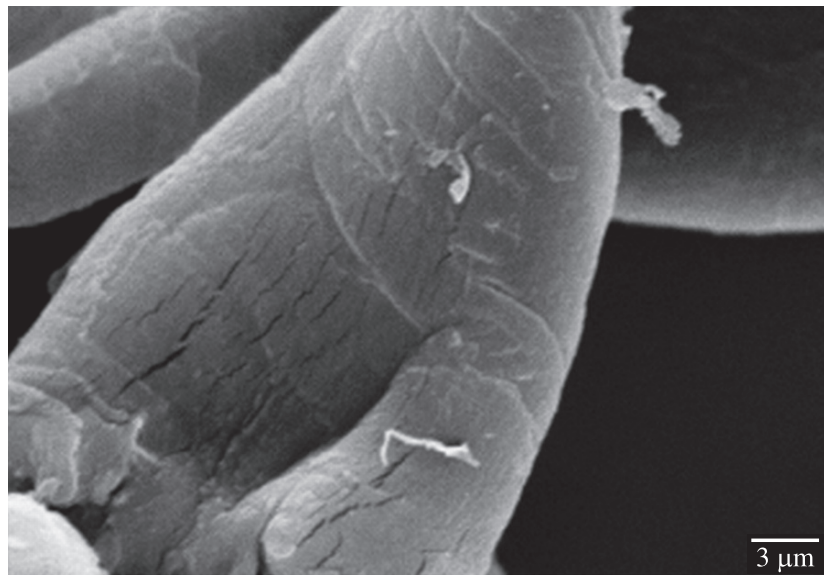

(d)

Figure 1. SEM images of untreated ( $a$ and $b$ ) and mercerized linters cellulose ( $c$ and d).

adsorption, as mercerization increases the specific surface area of the fiber, making the hydroxyl groups of the cellulose chains more accessible to solvents ${ }^{[1,39]}$. In the present work, these changes enabled the dissolution of linters cellulose in $\mathrm{DMAc} / \mathrm{LiCl}$, the solvent system used for the acetylation reaction.

The penetration of $\mathrm{NaOH}$ seems to first start within the amorphous regions of cellulose, which are more accessible, and in a second step the non-crystalline region of cellulose, which leads to separation of part of the chains, decreasing the crystallinity. Treatment with $20 \% \mathrm{NaOH}$ reduced the value of Ic from 79 to $73 \%$ (Table $1, \mathrm{X}$ ray diffractogram not shown)

\section{Characterization of cellulose acetates}

The DS values of the cellulose acetates were calculated by means of the ratio between the area corresponding to the NMR proton resonance of the glucose ring $(\delta 2.60-5.20 \mathrm{ppm})$ and the corresponding resonance area of the methyl protons of the acetate group $(\delta 1.80-2.20 \mathrm{ppm})$, (spectra not shown $)^{[34]}$. The DS values of the cellulose acetates ranged from 0.6 to 1.9 .

Even when a solution of cellulose appears visually homogeneous, there may be some degree of aggregation (irreversible process) and/ or association (reversible process) of the dissolved polymer chains at a colloidal level. In this case, the cellulose chains are not in "true" solution, but homogeneous conditions of reactions are still preferable, as the distribution of the substituents along the chains will normally be more uniform than in a heterogeneous reaction. It is important to find the pretreatment and dissolution conditions
Table 1. Degree of polymerization (DPv) and crystallinity index (Ic) of untreated and mercerized linters cellulose

\begin{tabular}{lcc}
\hline \multicolumn{1}{c}{ Linters cellulose } & DPv & Ic (\%) \\
\hline Untreated & 408 & 79 \\
Mercerized & 358 & 73 \\
\hline
\end{tabular}

that maximize the molecular dispersion of the chains in solution, moreover because the phenomena of aggregation/association affect the efficiency of acetylation, since the hydroxyl groups that form H-bonds between chains will be much less available to react with $\mathrm{Ac}_{2} \mathrm{O}^{[11]}$. The conditions used herein were based on previous studies $^{[10,11]}$.

The $\mathrm{X}$ ray diffraction technique was employed to investigate the crystallinity of cellulose acetates (figures not shown). The results indicate that the Ic ranged from 33 to $65 \%$, but there is no correlation between Ic and the degree of substitution of cellulose acetates; however, for all cellulose acetates, Ic decreased compared to mercerized linters cellulose ( $\mathrm{Ic}=73 \%$, Table 1 ). This reduction in crystallinity occurs due to the higher volume of the acetyl group introduced through acetylation, when compared to the hydrogen of hydroxyl groups, which hinders chain packing.

The thermal decomposition of cellulose and its acetates with different DS were investigated by TGA. Figure 2 shows DTG curves of the linters cellulose, mercerized linters cellulose, and cellulose 
acetate with a DS of 0.8 . The curves related to other acetates (figures not shown) present similar behavior.

The thermal decompositions of cellulose and its derivatives consist of a series of reactions. The first step of weight loss, from

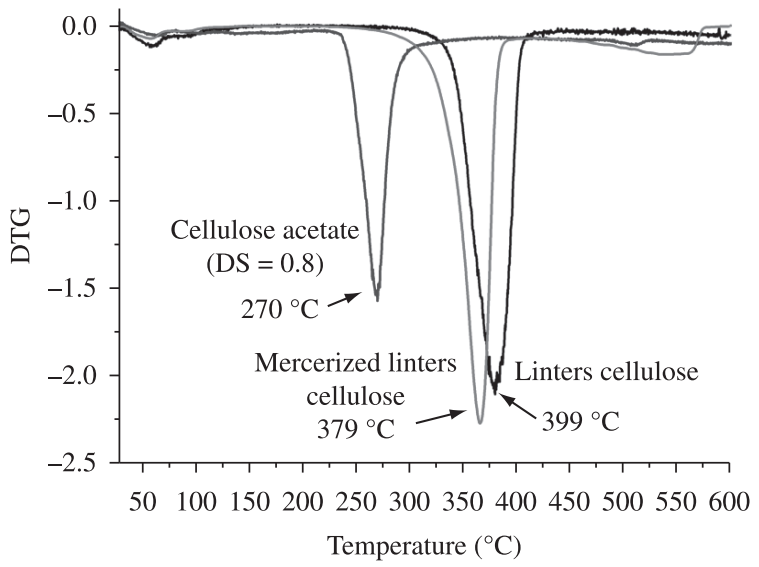

Figure 2. DTG curves of the linters cellulose, mercerized cellulose and cellulose acetate with a DS of 0.8 (atmosphere of $\mathrm{N}_{2} 20 \mathrm{~mL} / \mathrm{min}$, heating rate of $20^{\circ} \mathrm{C} / \mathrm{min}$ ). room temperature to $110^{\circ} \mathrm{C}$, is related to the evaporation of residual absorbed water. The second step ends near $450{ }^{\circ} \mathrm{C}$, and can be described by an abrupt mass loss stage that is related to the main thermal decomposition process ${ }^{[40,41]}$.

The peak temperature in the DTG curves (Figure 2) corresponds to the temperatures at which the rate of decomposition reaches the maximum value ${ }^{[41]}$.

According to the results obtained, untreated cellulose begins to decompose at a higher temperature $\left(\mathrm{T}_{\mathrm{i}}=368^{\circ} \mathrm{C}\right)$ when compared to mercerized cellulose $\left(\mathrm{T}_{\mathrm{i}}=307^{\circ} \mathrm{C}\right)$. It is seen that there is a significant difference between mercerized and untreated cellulose in relation to their respective thermal decomposition temperatures, which may be related to the difference in crystallinity between untreated and mercerized linters. In the crystalline regions of the polymer, the intermolecular hydrogen bonds between chains are stronger than those of non-crystalline regions, and require more energy to break before the decomposition process can proceed. This means that the higher proportion of crystalline domains in the untreated cellulose results in a higher thermal stability, when compared to mercerized linters. The non-crystalline region is more actively decomposed than the crystalline region, adding complexities in the thermal decomposition of cellulose ${ }^{[42]}$.
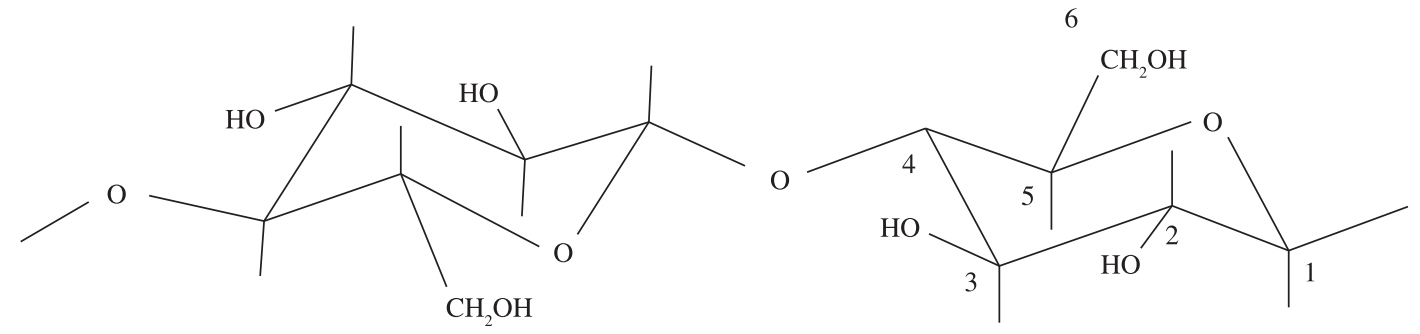

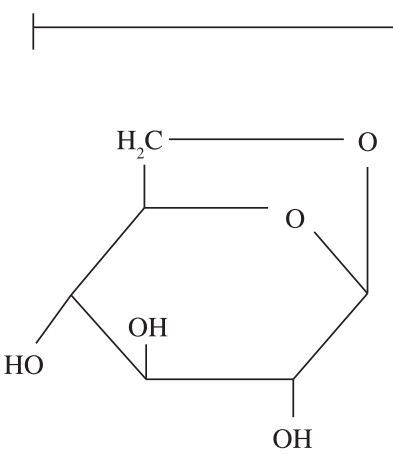

Levoglucosan

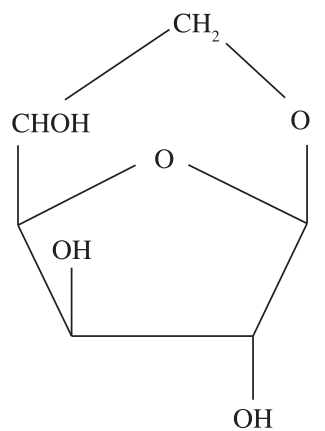

1, 6 - anhydroglucofuranose

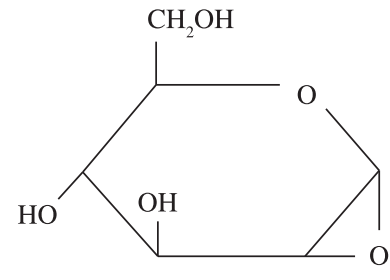

1,2 - anhydroglucose

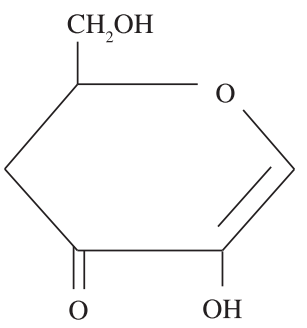

3 - desoxy - glucosanone

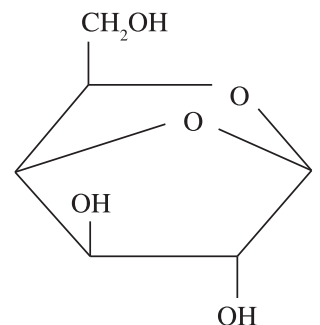

1, 4 - anhydroglucose

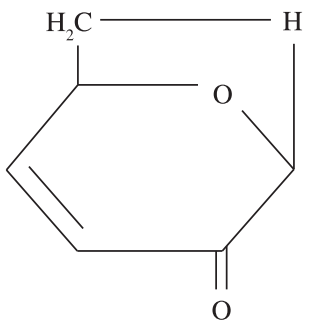

Levo - glucosanone

Figure 3. Anhydroglucoses and enones: Products of the thermal decomposition of cellulose ${ }^{[4]}$. 
The first reaction in the decomposition of cellulose involves dehydration and leads to anhydrocellulose, which can result from either inter- or intra-ring dehydration ${ }^{[43]}$. Figure 3 depicts the anhydroglucoses that can form as products of the thermal decomposition of cellulose.

The mechanism of the thermal decomposition of cellulose reveals the importance of the hydroxyl group connected to C6 in the decomposition process, which is involved in the reaction that leads the formation of levoglucosan (Figure 3).

Levoglucosan $(1,6$-anhydro- $\beta$-D-glucopyranose) is the primary product of cellulose pyrolysis; however, other anhydroglucoses (1,2-1,4-anhydro-glucose, 1,6-anhydroglucofuranose, and enones), furan, and furan derivatives are also produced ${ }^{[44,45]}$. Levoglucosan formation from cellulose pyrolysis is produced by the scission of the 1,4 glucosidic linkage in the cellulose, followed by intramolecular rearrangement of the monomer units ${ }^{[46]}$.

Water formation from cellulose occurs at various temperatures because there is a number of different water producing reactions in the decomposition of this polysaccharide. Scheirs and coworkers ${ }^{[43]}$ showed some possibilities for the chemical elimination of water from cellulose that results in the formation of levoglucosan or 1,6-anhydroglucose. The thermostability of cellulose may be influenced by the introduction of acetates groups.

The plot of $\ln [\ln [1 /(1-\alpha)]]$ vs. $1 / \mathrm{T}$ (Equation 10), in the temperature range that the main thermal decomposition step occurs (from 250 to $480{ }^{\circ} \mathrm{C}$ ), is shown in Figure 4 for untreated and mercerized linters cellulose, as well as for cellulose acetate with a DS of 1.1. The Ea were determined from the slopes of the obtained linear curves (Figure 4) ${ }^{[46]}$. Similar curves were obtained for the other cellulose acetates (figures not shown).

It can be seen that the $\mathrm{Ea}$ of untreated linters cellulose $\left(158 \mathrm{~kJ} \mathrm{~mol}^{-1}\right)$ is lower than that of mercerized cellulose (187 $\mathrm{kJ} \mathrm{mol}^{-1}$ ). In cellulose I (untreated linters), whose chains are orientated in parallel, the $-\mathrm{CH}_{2} \mathrm{OH}$ groups of adjacent chains have the same conformation, while in cellulose II (mercerized linters), the adjacent chains have these groups in different positions (antiparallel structure $)^{[11,18-21]}$. Despite the lower crystallinity of mercerized linters, due to the different $-\mathrm{CH}_{2} \mathrm{OH}$ group orientations in cellulose II, the hydrogen bonds among their chains are stronger than those of the cellulose I chains (untreated linters), which results in cellulose II being a more stable structure compared to cellulose I. This configurational difference results in a higher Ea for the thermal decomposition of mercerized linters. Considering the Ea values obtained from the thermogravimetric analyses described in literature, it can be inferred that the data discussed herein are inside the range mentioned for celluloses obtained from different sources, that is, from 179.5 to $190.6 \mathrm{~kJ} \mathrm{~mol}^{-1[47]}$ and from 140 to $155 \mathrm{~kJ} \mathrm{~mol}^{-1[48]}$.

A correlation between the Ea of mercerized cellulose and its acetates is not so easy, because the presence of acetyl groups introduces the possibility of other reactions; however, taking into account that the $\mathrm{C} 6$ is the more reactive carbon under the conditions used in the present study ${ }^{[11]}$, and the importance of $-\mathrm{C} 6 \mathrm{OH}$ in the thermal decomposition of the chain backbone, some considerations can be made.

The reactivity of $\mathrm{OH}$ in the $\mathrm{C} 6$ position is favored, when compared to $\mathrm{C} 2$ and $\mathrm{C} 3$, because this group is the least sterically hindered of the AGU unity ${ }^{[49]}$. Acetates samples here described were prepared in $\mathrm{DMAc} / \mathrm{LiCl}$ following previous study ${ }^{[11]}$, and the order of reactivity observed for all samples was $\mathrm{C} 6>>\mathrm{C} 2>\mathrm{C} 3$, confirming the higher reactivity of $\mathrm{C} 6 \mathrm{OH}$. The lower reactivity of $\mathrm{C} 3 \mathrm{OH}$, when compared to $\mathrm{C} 2 \mathrm{OH}$, can be related to the fact the first hydroxyl group can still be involved in the intramolecular hydrogen bond $^{[11]}$.

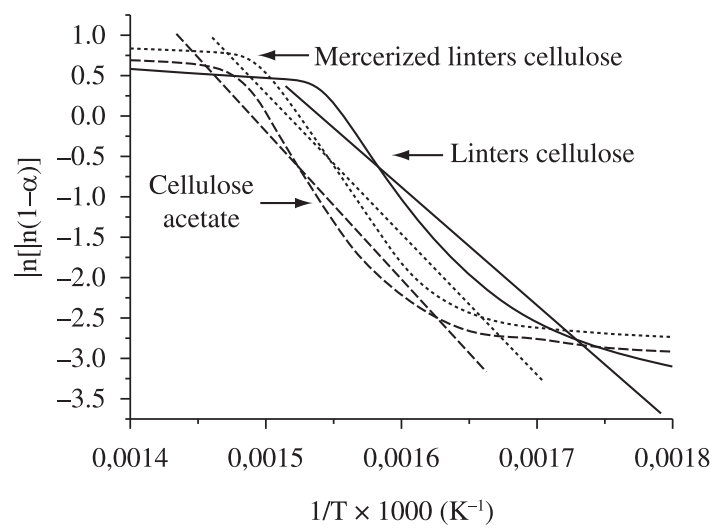

Figure 4. $\ln [\ln [1 /(1-\alpha)]]$ vs. $1 / \mathrm{T}$ using Broido's equation for untreated and mercerized linters cellulose and cellulose acetate with a DS of 1.1.

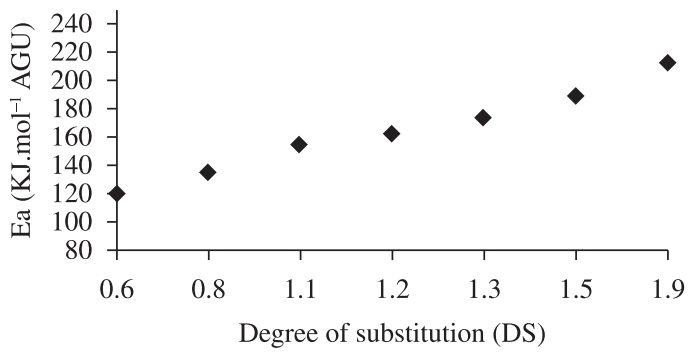

Figure 5. Apparent activation energy (Ea) vs. degree of substitution (DS) of cellulose acetates.

The $\mathrm{C} 6 \mathrm{OH}$ takes part in the first step of cellulose decomposition, leading to levoglucosan formation (Figure 3). The Ea for mercerized cellulose $\left(187 \mathrm{~kJ} \mathrm{~mol}^{-1}\right)$ decreased to the Ea for its acetates when the DS was varied from 0.6 to 1.2 , wherein the Ea ranged from nearly 120 to $160 \mathrm{~kJ} \mathrm{~mol}^{-1}$ (Figure 5). Considering that acetylation primarily occurs at $\mathrm{C}^{[11]}$ from DS of 0.6 to 1.2 , it can be considered that $\mathrm{C} 6$ is the most substituted when compared to $\mathrm{C} 2$ and $\mathrm{C} 3^{[11]}$. The obtained Ea suggest that thermal decomposition involving $\mathrm{C}^{6} \mathrm{COOCH}_{3}$ can contribute to a lower Ea, when compared to levoglucosan formation from $\mathrm{C} 6 \mathrm{OH}$.

Considering the set of acetates, under the conditions considered in the present work there is a good correlation between Ea and DS, where Ea increases as a function of the DS (Figure 5). The range of investigated DS (from 0.6 to 1.9) was chosen to evaluate acetates with diversified substitutions on $\mathrm{C} 6, \mathrm{C} 3$, and $\mathrm{C} 2$.

As the DS increases, C2 and C3 increase their individual DS and their Ea increase. Even the acetate with a DS of 1.9 has a higher $\mathrm{Ea}\left(\right.$ near $210 \mathrm{~kJ} \mathrm{~mol}^{-1}$ ) than the mercerized cellulose. $\mathrm{C} 2 \mathrm{OH}$ and $\mathrm{C} 3 \mathrm{OH}$ take part in the thermal decomposition reactions that result, for instance, in 1,2-anhydroglucose and 3-desoxyglucosanone (Figure 3), respectively. When acetyl groups are introduced onto these carbons, the mechanism of thermal decomposition changes, and the values of Ea found in the present study indicate that the thermal decomposition involving $\mathrm{C}_{2} \mathrm{COOCH}_{3}$ and $\mathrm{C}_{3} \mathrm{COOCH}_{3}$ requires more energy, when compared to $\mathrm{C} \mathrm{COOCH}_{3}$, contributing to a higher Ea.

\section{Conclusions}

Thermal decomposition behaviors and Ea values were evaluated by TGA and Broido's methods, respectively, for untreated and mercerized linters cellulose, as well as acetates synthesized in $\mathrm{DMAc} / \mathrm{LiCl}$ from alkali treated samples (DS from 0.6 to 1.9), under dynamic conditions. The Ea values obtained for untreated 
and mercerized celluloses, under the conditions used in the present study, indicate that the stronger hydrogen bonding present in the crystalline domains of cellulose II (mercerized linters) increase the corresponding Ea for thermal decomposition. The synthesis of acetates from low (0.6) to a higher (1.9) DS verified the influence of the distribution of the acetyl groups on $\mathrm{C} 2, \mathrm{C} 3$, and $\mathrm{C} 6$ on the Ea of thermal decomposition, under the conditions used in this study. It must be pointed out that the results herein provide important information regarding the thermal decomposition of untreated and mercerized linters cellulose, as well as that of their respective acetates; however celluloses and acetates from sources other than linters, or even linters with degrees of crystallinity different from the sample analyzed here, can present different behavior.

\section{Acknowledgements}

E. F. is grateful to CNPq (National Research Council, Brazil) for a research productivity fellowship and financial support, as well as to FAPESP (The State of São Paulo Research Foundation, Brazil) for financial support and for the doctoral fellowship for D. L. Morgado

\section{References}

1. Wei, Y. \& Cheng, F. - J. Appl. Polym. Sci., 106, p. 3624 (2007).

2. Napolitano, B. A.; Martins, A. F.; Visconte, L. L. Y. \& Nunes, R. C. R. Polímeros, 14, p.223 (2004).

3. Corti, G. S.; Botaro, V. R.; Gil, L. F. \& Gil, R. P. F. - Polímeros, 14, p.313 (2004).

4. Schurz, J. - Prog. Polym. Sci., 24, p.481 (1999).

5. Botaro, V. R.; Santos, C. G. \& Oliveira, V. A. - Polímeros, 19, p.278 (2009).

6. Ishii, D.; Tatsumi, D. \& Matsumoto, T. - Carbohydr. Res., 343, p.919 (2008).

7. Tosh, B.; Saikia, C. N. \& Dass, N. N. - Carbohydr. Res., 327, p.5 (2000).

8. Potthast, A.; Rosenau, T.; Sartori, J.; Sixta, H. \& Kosma, P. - Polymer, 44, p.7 (2003).

9. Potthast, A.; Rosenau, T.; Buchner, R.; Roder, T.; Ebner, G.; Bruglachner, H.; Sixta, H. \& Kosma, P. - Cellulose, 9, p.41 (2002).

10. Ramos, L. A.; Assaf, J. M.; El Seoud, O. A. \& Frollini, E. Biomacromolecules, 6, p.2638 (2005).

11. Ass, B. A. P.; Belgacem, M. N. \& Frollini, E. - Carbohydr. Polym., 63, p.19 (2006).

12. Ciacco, G. T.; Ass, B. A. P.; Ramos, L. A. \& Frollini, E. - e-Polymers, 22, p.1 (2008).

13. Liu, C. F.; Sun, R. C.; Zhang, A. P.; Ren, J. L.; Wang, X. A.; Qin, M. H.; Chao, Z. N. \& Luo, W. - Carbohydr. Res., 342, p.919 (2007).

14. Turbak, A. F.; El-Kafrawy, A.; Snyder, E. W. \& Auerbach, A. B. U.S. Patent 4.302.252 (1981).

15. Turbak, A. F. - "Wood and agricultural residues", Soltes, E. J. (ed.), Academic Press, New York (1983).

16. Klemm, D.; Philipp, B.; Heinze, T.; Heinze, U. \& Wagenknecht, W. "Comprehensive cellulose chemistry", in: Functionalization of cellulose, v.1, Wiley-VCH, Germany (1998).

17. Ass, B. A. P.; Ciacco, G. T. \& Frollini, E. - Bioresour. Technol., 97, p.1696 (2006).

18. Nishiyama, Y.; Sugiyama, J.; Chanzy, H. \& Langan, P. - J. Am. Chem. Soc., 125, p.14300 (2003).

19. Kroon-Batenburg, L. M. J. \& Kroon, J. - Glycoconjucate J., 14, p.677 (1997).
20. Shibazaki, H.; Kuga, S. \& Okano, T. - Cellulose, 4, p.75 (1997).

21. Langan, P.; Nishiyama, Y. \& Chanzy, H. - Biomacromolecules, 2, p.410, (2001).

22. Dinand, E.; Vignon, M.; Chanzy, H. \& Heux, L. - Cellulose, 9, p.7 (2002).

23. Rinaudo, M. \& Reguant, J. - "Natural polymers and agrofibers based composites”, Frollini Leão, E. A. \& Mattoso, L. H. C. (ed.), São Carlos, São Paulo, Brazil (2000).

24. Paula, M. P.; Lacerda, T. M. \& Frollini, E. - Express Polym. Lett., 2, p.423 (2008)

25. Britto, D. \& Campana-Filho, S. P. - Thermochim. Acta, 465, p.73 (2007).

26. Bozanic, D. K.; Djokovic, V.; Bibic, N.; Sreekumari Nair, P.; Georges, M. K. \& Radhakrishnan, T. - Carbohydr. Res., 344, p.2383 (2009).

27. Hanna, A. A.; Basta, A. H.; El-Saied, H. \& Abadir, I. F. - Die Angewandte Makromolekul. Chem., 260, p.1 (1998).

28. Levi, D. W.; Reich, L. \& Tee, T. - Polym. Eng. Sci., 5, p.135 (1965).

29. Shen, D. K. \& Gu, S. - Bioresour. Technol., 100, p.6496 (2009).

30. Sairam, M.; Sreedhar, B.; Mohan Rao, D. V. \& Palaniappan, S. - Polym. Advan. Technol., 14, p.477 (2003).

31. Lucena, M. C. C.; Alencar, A. E. V.; Mazzeto, S. E. \& Soares, S. A. Polym. Degrad. Stab., 80, p.149 (2003).

32. Buschle-Diller, G. \& Zeronian, S. H. - J. Appl. Polym. Sci., 45, p.967 (1992).

33. "Viscosity of pulp (capillary viscosimeter method), T230 om-89", in: TAPPI test methods, Tappi Press, Atlanta (1990).

34. Edgar, K. J.; Arnold, K. M.; Blount, W. W.; Lawniczak, J. E. \& Lowmann, D. W. - Macromolecules, 28, p.4122 (1995).

35. Britto, D. \& Campana-Filho, S. P. - Polym. Degrad. Stab., 84, p.353 (2004).

36. Dahiya, J. B.; Kumar, K.; Muller-Hagedorn, M. \& Bockhorn, H. - Polym. Int., 57, p.722 (2008)

37. MacCallum, Jr. - "Thermogravimetric analysis", in: Comprehensive polymer science, Allen, G. \& Bevington, L. C. (ed.), cap.37, Pergamon Press, Oxford (1989).

38. Broido, A. - J. Polym. Sci. Part A-2, 7, p.1761 (1969).

39. Pusic, T.; Grancaric, A. M.; Sljacic, I. \& Ribitsch, V. - J. Soc. Dyers Colour., 115, p.121, (1999).

40. Huang, M-R. \& Li, X-G. - J. Appl. Polym. Sci., 68, p.293 (1998).

41. Flaqué, C. \& Montserrat, S. - J. Appl. Polym. Sci., 74, p.201 (1999).

42. Severian, D. - "Polysaccharides: structural diversity and functional versatility", Marcel Dekker, New York (2005).

43. Scheirs, J.; Camino, G. \& Tumiatti, W. - Eur. Polym. J., 37, p.933 (2001).

44. Fengel, D. \& Wegener, G. - "Wood: chemistry, ultrastructure, reactions", Walter de Gruyter, Berlin (1989).

45. Li, S.; Lyons-Hart, J.; Banyasz, J. \& Shafer, K. - Fuel, 80, p.1809 (2001). 46. Qu, X.; Wirsén, A. \& Albertsson, A-C. - Polymer, 41, p.4841 (2000).

47. Kaloustian, J.; Pauli, A. M. \& Pastor, J. - J. Therm. Anal. Calorim., 63, p.7 (2001).

48. Milosavljevict, I. \& Suuberg, E. M. - Ind. Eng. Chem. Res., 34, p.1081 (1995).

49. Marson, G. A. \& El Seoud, O. A. - J. Appl. Polym. Sci., 74, p.1355 (1999).

Enviado: 05/05/10

Reenviado: $28 / 07 / 10$

Aceito: $26 / 08 / 10$

DOI: $10.1590 / \mathrm{S} 0104-14282011005000025$ 